\title{
Vehicle Network Technology Application in Logistics Management Research
}

\author{
Wang Aijing \\ Management Department, Guangzhou Vocational Collage of Technology \& Business Guangzhou City, China \\ Waj12@sohu.com
}

\begin{abstract}
The domestic consumer price index is rising continuously, logistics is considered one of the factors is the impact of the high price index. The analysis of each industry logistics costs constitute the highest proportion of most transportation costs. However, the transport industry tariffs are generally low, is not conducive to the healthy development of the transport industry. Vehicle networking technology of choice in this paper, the application of the Internet of Things, through research situation analysis, from existing logistics costs constitute analysis start using car network key technologies from the transportation costs, warehousing costs, management fees, and fuel consumption, labor fees aspects the reasonable control of the logistics cost, so as to resolve the plight of logistics and high cost operators.
\end{abstract}

Keywords-Vehicle networking, logistics, transportation costs

\section{A HIGH COST OF LOGISTICS OPERATIONS ANALYSIS}

In recent years, the overall level of the domestic consumer price index (CPI) rising continuously, rose 5.4\% in 2011, and throughout 2012 price pressures significantly reduced compared to 2011 from January to November, the average national consumer price level than last year rose $2.7 \%$ over the same period. Worthy of note is the focus previous price increases in food and housing prices, energy or industrial raw materials, since March 2011, logistics has become one of the focal logistics at least considered the factors that affect the high price index rising prices is attributed for industry development lag caused by the high cost. The reason, not simply by road charges, fuel prices, and repeated charges to explaining the problem. Logistics industry should further accelerate the industrial optimization and upgrading of the pace of R \& D and focus on new technology, promotion and application of new technologies in order to resolve the plight of logistics and high cost operators in the industry.

(1) Social logistics costs constitute Analysis

National total social logistics costs in 2011 of 8.4 trillion yuan, a year-on-year growth of $18.5 \%$, an increase of 1.8 percentage point increase over the previous year. Transportation costs of 4.4 trillion yuan, a year-on-year growth of $15.9 \%$, an increase of 0.4 percentage point increase over the first three quarters, an increase of 1.9 percentage points over the previous year, the share of total social logistics costs accounted for $52.8 \%$, down 1.2 percentage points; management cost of 1 trillion yuan, a year-on-year growth of $18.7 \%$, the share of total social logistics costs accounted for $12.2 \%$, year-on-year increase of 0.1 percentage points; custody fees of 2.9 trillion yuan, a year-on-year growth of 22.6\%, an increase of 2.1 percentage point increase over the previous year, accounting for the total social logistics costs accounted for $35 \%$, year-on-year increase of 1.1 percentage points.

\section{Total Socil Logistics}

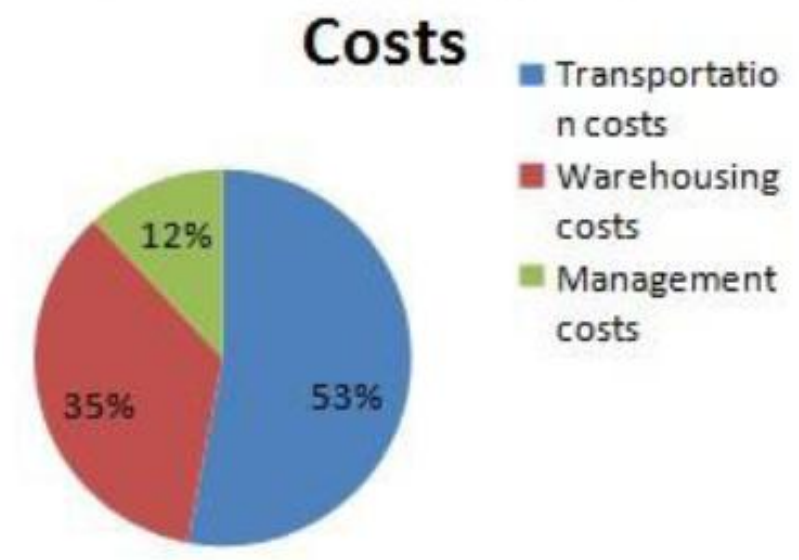

Figure 1: 2011 total social logistics costs Data Source: National Development and Reform Commission, the National Bureau of Statistics, China Logistics and Purchasing Federation released

(2) High transport costs, tariffs low Analysis Shown in Figure 1, it is necessary to reduce the total social logistics costs, accounted for $53 \%$ of transport costs would have reduced. But the fact is that the transport market tariffs are generally low.

Relevant statistics, the 10 years between 2001 to 2011, the Chinese social logistics, transportation costs from 1.08 trillion yuan in 2001, increased to 4.4 trillion yuan in 2011 , an increase of 4 times. The same period China cargo in accordance with the weight increase of 2.6-fold greater increase in the average transport distance, up to 2-3 times, which analyzed Chinese cargo market units in the case of labor costs have risen sharply, oil prices surged cargo transport per kilometer The cost of virtually no growth. Also reflect the overall situation of the freight industry in China is not optimistic about the low tariffs, the rising cost of doing business the transport enterprise meager profit or loss, is not conducive to the long-term and sustainable development of the industry as a whole. 


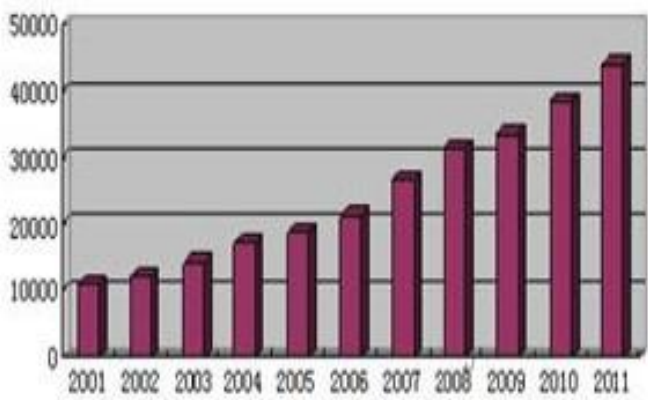

Figure 2: logistics and transport cost changes in 200

\section{- 2011 (Unit: 100 million yuan)}

Source: Bureau of Statistics From the total social logistics point of view, Chinese total social logistics growth in the decade grew eight-fold, and the transportation costs for the same period increased by only 4 times, relative to the total value of logistics items decade unit transportation costs decreased by half, whichIt is a normal phenomenon. View from freight, freight accounted for the highest proportion of the total logistics costs, general comprehensive analysis to calculate social logistics costs, transportation costs accounted for nearly $50 \%$ of the proportion in which the shipping of some products is higher than the production costs of the product.

The total social logistics costs to GDP ratio in 2011 was $17.8 \%$, flat year on year, and run the logistics of the socio-economic costs are still higher. American and European countries accounted for only 8.9\%, the proportion of China's logistics costs as a percentage of GDP for every 1 percentage point lower energy consumption in the transport of goods, warehousing, more than 100 billion yuan, while increasing social benefits of about 130 billion yuan. Therefore, the high cost of logistics has become an important factor to hinder domestic enterprises to participate in international competition.

\section{APPLICATION VEHICLE NETWORKING TECHNOLOGY, WAYS TO REDUCE LOGISTICS COSTS}

(1)Through real-time monitoring system to reduce transportation costs The cost of the vehicle during transport is mainly constituted by the gas, toll, vehicle maintenance costs, staff wages, etc.. The application vehicle networking terminal Quick Stats running distance of the vehicle, the vehicle through the toll station, pay the road toll, where refueling, to effectively monitor the driver's behavior, reduce transportation costs. For the loading and unloading of cargo, damage to the goods vehicle transport process will lead to increased transport enterprises Payout costs through networked terminals installed in the vehicle, the car, the dispatch center during transport real-time monitoring of the operation of the vehicle, reducing lost during transport The phenomenon of the goods, damaged goods, and indirectly reduce transport costs.

By electronic tags mounted on a vehicle by wireless radio frequency identification technology can be collected from time to time and the perception area within vehicle's speed, the distance between vehicles, road share information. So as to provide accurate input information intersection traffic signal control. In addition, through the installation of temperature and humidity, light intensity, gas detection sensor to the terminal node, can also carry out road conditions, visibility, vehicle exhaust pollution detection. According to the research, when the poor roads, motorists often need to step on the gas and brakes, each acceleration and deceleration of the fuel consumption is three times the usual gas-guzzling. If we average speed by 20 kilometers per hour to $30-40 \mathrm{~km}$, the average fuel consumption can be reduced by $20 \%-40 \%$.

(2) Vehicle networking technology to reduce the cost of vehicle management

Vehicle networking technology, each car as an information source is connected to the network by means of wireless communication, the running state of the vehicle through the vehicle networking terminal, real-time location information and road information uploaded to the dispatch center, real-time online vehicle monitoring and scheduling, traffic management departments realize low cost vehicle, the unified management of the road. To ensure the effective implementation of the plan of the vehicle, so as to realize the intelligent management of vehicles and traffic planning the best travel route, to reducing vehicle uptime and drivers operating time, reduce vehicle transportation costs and labor costs.

(3) Improving the truck operational efficiency, save time and cost, and reduce warehousing costs

ETC vehicle networking technology to make transportation faster and more reliable than ever, and competition in the transport market, the total level of freight rates decline. This, manufacturers, wholesalers and retailers advanced inventory management methods (such as JIT, MRP, ECR, etc.) to create favorable market conditions. Enterprises to adopt multiple batches, less bulk orders to reduce inventory levels and to static inventory into dynamic inventory, while reducing transportation costs, but also reduces the cost of warehousing.

According to 2011 statistics, the load rate about 38\% of my vehicle operators, which greatly increased the cost of transportation enterprises, also caused by the huge cost of warehousing. Networking through the car to change the status quo supply information and car source information is extremely asymmetric. Real-time vehicle information to avoid the phenomenon of no-load of the vehicle, reducing the load rate of vehicles and improve vehicle utilization, dynamic distribution of goods, to reduce the storage space, time, and speed up the speed of the flow of goods and commodities.

According to estimates, the using ETC prevailing highway toll crossing cycle fuel consumption and exhaust emissions can be reduced by about 50\% the crossing 
capacity increase 4-6 times. 20 times calculated using the ETC lane to one of the owners a week, about 15.3 liters per year can be fuel-efficient. ETC lanes 20 times (the inlet and outlet of the 10) in the same week to an owners annual savings of about 14 hours. Thus shortening the transit time, to a certain extent, will reduce warehousing costs.

(4) The logistics vehicle transport process transparent management to reduce labor costs, improve service quality

Vehicle networking technology can be implemented on the transport process transparent management, to show logistics enterprises in high-quality logistics services, which attract a large number of sources. Specific transport process transparent management by IT, logistics and transport vehicles, collecting, displaying, exchange, and thus be able to improve the management of the entire logistics vehicle technology, running. This transport process transparent way to completely solve the a freight logistics vehicle management difficulties, loosely development status quo, to truly improve the quality of service of the logistics and transport industry. Have a very direct relationship between the logistics vehicle transport process transparent management for cost savings. Such as scheduling cost, labor cost savings.

\section{EXTENDED VEHICLE NETWORKING TECHNOLOGY APPLICATIONS TO THE IMPLEMENTATION OF MEASURES TO REDUCE LOGISTICS COSTS}

(1) Establish win-win situation networking business model Vehicle networking relates to all walks of life, to promote the development of the vehicle networking business model to create a win-win situation is a key element of the development process, is to promote the car to the core of the network of long-term effective development. Business model to achieve a win-win situation, the need to consider the vehicle networking truly become the driving force of a business, rather than an administrative force. All aspects of all those involved in the construction and operation of vehicle networking can benefit from access to appropriate commercial return to the car network sustained, healthy and rapid development, thereby reducing the cost of logistics.

At the same time, on the basis of enterprises to use the car networked flow of information and technology, and take full account of the construction of logistics infrastructure and its dynamic shared on management concepts, business processes, basic resources and systems hardware and software integration to form their own core competitiveness, establish an efficient, accurate car-based networking works.

(2) Further integrated logistics enterprise application development space vehicle networking technology Figure 3,drawing on data analysis of the relationship of the size of the enterprise in the United States in 2001 and logistics costs, the larger the enterprise, lower logistics costs, logistics enterprises should be specialized, large-scale, intensive development. Of course, not a simple linear relationship between profit growth due to economies of scale, often more than the growth in sales, logistics cost savings brought profits contained in them. Therefore, while seeking to reduce logistics costs should moderate expansion of the scale of the development strategy of differentiation or decentralization strategy, companies only have a certain scale, vehicle networking technology will play a cost-effective.

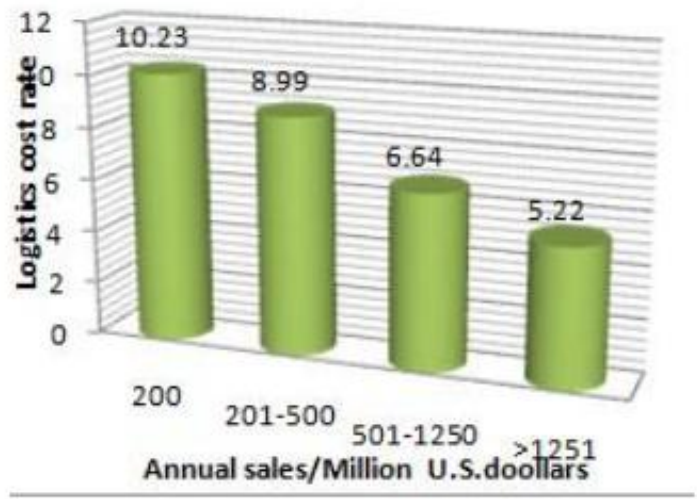

Figure 3 : logistics costs and the scale of the relationship (3) Government departments in addition to the macro-policy support, should also increase the vehicle networking information platform building efforts

The State of Things has been included in the national long-term development planning, strategic emerging industries and the major issue "Experience China" vehicle networking as the operability of the strongest parts of the Internet of Things, in recent years at all levels of government to promote such as: a wide range of vehicle networking standard system, the R \& D base, industry applications.

Logistics companies to win a small profit margin, highly competitive logistics market vehicle networking technology, to strengthen cost management is necessary and important. Lower logistics enterprises within the extent of information technology software applications due to the low level of domestic logistics industry, on the one hand, on the other hand between the logistics enterprise information platform, the low level of information sharing, which are in desperate need To logistics enterprises through increased investment, to carry out the construction of information technology, import of professional information management concepts and hardware facilities, however, the cost of vehicle networking technology includes not only the construction cost of the RFID system also includes the integration of computer communications equipment, receiving equipment, data processing platform, system integration building. These relatively low profit margins of the logistics industry in terms of its input costs are difficult to bear, so the government should increase efforts in building the vehicle networking information platform, allow more SMEs sharing platform information, to avoid waste of resources and duplication of construction, coordinate the various industries, the interests of all regions. 


\section{REFERENCES}

[1] Wang Jianqiang, Wu Chen Wen, Li Xiaojun. vehicle networking architecture and key technologies. Micro-computer information. 2011.4.156-158

[2] Shi Xiaoping, Huang Airong, Zhang Tao car networked sensing technology research progress. Hubei Automotive Industries Institute .2011.3.39-44

[3] Weng Xingang genesis of China's social logistics costs remain high in China Logistics and Purchasing .2011.14.68-69 [4] serve for Wang Guanyu, Jiao Yuntao Things technology in the field of modern logistics automation technology and application of .2011.

[5] Pan Yaqian of Things application instance and economic benefits and impact on the Chinese economy. Economic Research .2011.8

[6] Cui Xiaoyun. Logistics enterprises profit model based on Internet of Things. BUSINESS .2011.28.36-37

[7] SCHMIDT R, LEINMULLER T, SCHOCH E, et al. Exploration of Adaptive Beaconing for Efficient Intervehicle Safety Communication [J]. IEEE Network, 2010, 24(1): 14-19.

[8] YE F, YIM R, ROY S, et al. Eficency and Reliability of One-Hop Broadcasting in Vehicular Ad Hoc Networks [J].IEEE Journal on Selected Areas in Communications, 2011,29(1): 151-160.

[9]Ardalan Vahidi and Azim Eskandarian. Research Advances in Intelligent Collision Avoidance and Adaptive Cruise Control. IEEE TRANSACTIONS ON INTELLIGENT TRANSPORTATION SYSTEMS, VOL. 4, NO. 3, SEPTEMBER 2003

[10] HUANG C, FALLAH Y, SENGUPTA R, et al. AdaptiveIntervehicle Communication Control for Cooperative Safety Systems[J]. IEEE Network, 2010, 24(1): 6-13. 